\title{
Verification of Computer Simulink-Model for Electromechanical System of Armament Complex Guidance of Combat Vehicle
}

\author{
Yaroslav Paranchuk ${ }^{a, *}$, Pavlo Evdokimov ${ }^{b}$, Oleksiy Kuznyetsov $^{b}$, Volodymyr Tsjapa $^{a}$ \\ ${ }^{a}$ Lviv Polytechnic National University, S. Bandera St ., 12, Lviv, 79013, Ukraine \\ ${ }^{b}$ Hetman Petro Sahaidachny National Army Academy, Heroes of Maidan St., 32, Lviv, 79026, Ukraine
}

Received: January 17, 2020. Revised: March 11, 2020. Accepted: March 18, 2020.

(C) 2020 The Authors. Published by Lviv Polytechnic National University.

\begin{abstract}
The improvement of existing electromechanical guidance systems of the armament complex of combat vehicles should be implemented in the direction of increasing the speed and accuracy of positioning. The paper deals with the lifting mechanism of guidance of the package of guides of the multiple rocket launcher BM-21, which is a unit of the armament of the Armed Forces of Ukraine and is typical for many samples of weaponry. Based on the experimentally obtained time dependencies of the coordinates of the existing electromechanical system for providing a vertical motion of a package of guides, the parameters and the transfer functions of its elements have been identified, which have been implemented in the mathematical and computer Simulink-model. The comparison of the processes of changes of coordinates in the guidance process obtained by means of the created computer model and on the operating combat machine has been carried out. The comparisons of the obtained results have shown that the sufficient accuracy of coincidence of the time dependences of the coordinates of the electromechanical guidance systems is attained.
\end{abstract}

Keywords: armament guidance system; positioning accuracy; performance; computer model.

\section{Definition of the research problem}

Modern electromechanical systems of guidance, positioning, and tracking of an armament complex (responsible precise or powerful drives of individual weapons, etc.) are subjected to increased requirements for their performance, static and dynamic positioning accuracy, nature of the transition process, energy characteristics, automation level, etc. [1], [2], [3]. The mentioned indicators can be improved only on the basis of the integrated system approach [4], [5]. One of the expedient ways of obtaining the best solutions based on the specified approach is the use of mathematical and computer simulations [6]. Being performed on computer models, the optimization procedures, taking into account the constraints imposed on the parameters, indicators, and coordinates of the designed electromechanical system, allow us to obtain the structural, system-technical solutions and optimal values of variational parameters for the most complete implementation in the system of guidance of the set requirements to the indicators of its dynamics, statics, reliability, and energy efficiency.

\section{Analysis of the recent studies and publications on the problem}

According to the results of research and the experience of operation of a combat vehicle of multiple rocket launcher, the existing guidance system based on the electric drive according to the "rotary amplifier - direct current (DC) engine" scheme used on this vehicle has exhausted its capacity to increase performance and has the boundarypossible indicators of dynamics and statics of regulation of a package of launch for such systems. To improve the

*Corresponding author. Email address: yparanchuk@yahoo.com

This paper should be cited as: Y. Paranchuk, P. Evdokimov, O. Kuznyetsov, V. Tsjapa. Verification of computer Simulink-model for electromechanical system of armament complex guidance of combat vehicle. Energy Engineering and Control Systems, 2020, Vol. 6, No. 1, pp. 43 - 50. https://doi.org/10.23939/jeecs2020.01.043 
specified indicators, we propose to replace the rotary amplifier with a reversible pulse-width converter and to design the control system as a three-circuit positioning system with the subordinate coordinate control. The specified refinement approach significantly improves the electric power of the electric drive, improves its overall dimensions, reduces inertia, and provides wider functionality with the optimal positioning control (guidance process) by the criteria of dynamic and static positioning accuracy. At the same time, the high energy efficiency of such positioning electric drive should be achieved, which would be ensured by the implementation of the optimal law of motion of the package of launch from the initial position to the final one while minimizing the dynamic load and power losses in the power elements of the electric drive.

The realization of the specified possibilities in the positioning electric drive of the mechanism of guidance of the package of launch is complicated by the action of external influences (perturbations) and other factors, such as the change of the moment of load at different filling of the package of launch with rockets, depending on the angle of guidance, the changes in frictional torque, the changes in elastic moment caused by balancing (torsion type) mechanism, the available backlashes in kinematic transmission, the changes in the moment of resistance, etc. The effect of the specified factors and external influences is nonlinear and not regular, characterized by uncertainty [7], [8].

One of the expedient approaches to optimize the process of positioning a package of launch and obtain the high static and dynamic guidance accuracy is to use a subordinate control system with the implementation of a fuzzy control position, i.e., an intelligent controller or corrector operating on the basis of fuzzy logic.

Alternatively, it is advisable to use a fuzzy position controller and the PI speed controller and current in the subordinate speed and current control circuits. For comparison, it would be expedient to track the positioning dynamics with the classic PID-controller of a position.

All of the aforesaid confirms the relevance and expediency of creation of a methodology for computer synthesis, optimization, adaptation, and analysis based on the use of high-precision nonlinear models of the guidance system taking into account the constraints on the ranges of change of its coordinates and taking into account the real parametric and coordinate perturbations with the aim of improving the existing and creating new more sophisticated structures of electromechanical guidance systems, which would fully meet the modern rigid requirements for indicators of dynamics, statics, energy efficiency, reliability and the requirements for overall dimensions indicators of the electromechanical guidance system.

\section{Aim of the research}

The purpose of this work is to develop a high-precision nonlinear model of the existing electromechanical control system of the guidance mechanism of an armament complex of a combat vehicle, which is under the influence of uncertain parametric changes and to prove its verification in order to carry out with its use the analysis of the dynamics indicators of the existing electromechanical system, and substantiation of rationality of the structure and the principles of control in direction of improving the dynamics of movement and statics of the guidance mechanism, in particular, to improve the accuracy of control of this system.

\section{Results and their discussion}

To perform the tasks outlined above, experimental investigations of the dynamics of motion and positioning of a package of launch have been performed on the operating combat vehicle when working out various setting and disturbing influences [9]. The main purpose of these investigations was to obtain the values of the parameters, the transfer functions or differential equations of elements of the electromechanical system of the mechanism of vertical guidance of the package of launch. This information is necessary for the mathematical description and construction of a computer Simulink-model of the electromechanical system of the lifting mechanism of a combat vehicle.

The investigated electromechanical guidance system of a combat vehicle is made on the basis of the electric drive according to the scheme "generator-engine" with potentiometric control, in which as an amplifier a rotary amplifier serves. This system can provide a speed adjustment range of $D=200: 1$. The main components of an electromechanical vertical guidance system are the following devices:

1) setting (potentiometer and voltage divider);

2) amplifying (polarized relay and rotary amplifier of EMP-12PM type);

3) acting (DC engine with independent excitation of MI-22M type); 
4) stabilizing (separate winding of the polarized RP-5 relay and auxiliary EMP-12PM winding);

5) transmitting (planetary gearbox, safety clutch, lifting gear clutch, cogged cradle sector, and balancing mechanism).

The functional block diagram of the lifting mechanism of the combat vehicle BM-21 is shown in Fig.1.

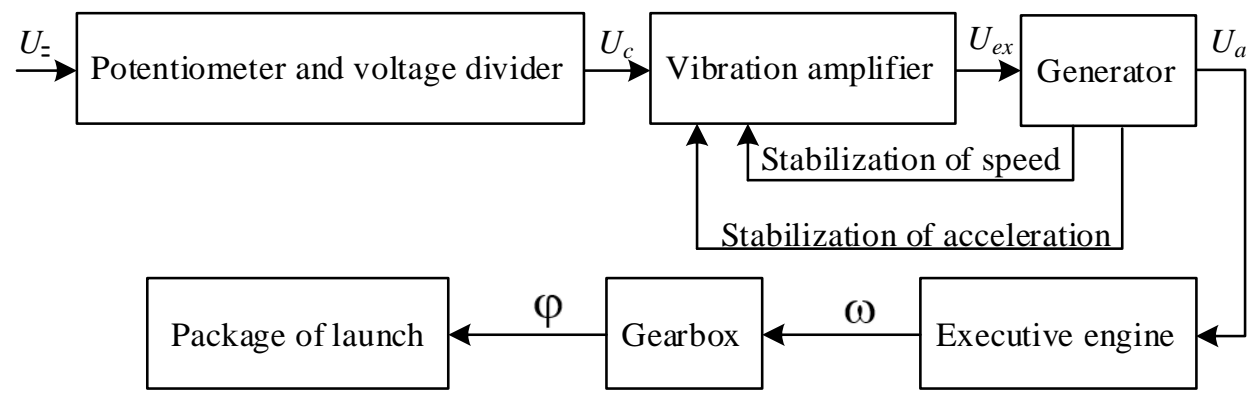

Fig.1. Functional block diagram of the lifting mechanism of the combat vehicle BM-21.

In order to increase the stiffness of the mechanical characteristics of the system, negative feedback with respect to the engine speed is implemented. To reduce the acceleration and deceleration time of the drive, as well as to improve the dynamics at low speeds (mainly in modes of adjusting the positioning angle of the guides to a given one), flexible feedback with respect to the voltage $U_{a}$ of the rotary amplifier was used. For the same purpose, the negative feedback with respect to the current of the drive actuator anchor is also implemented. The circuit is open by the position (guidance angle) of the package of launch. The control signal for moving the package of launch $U_{c}$ to a given guidance angle is formed by rotating the flywheel of the control panel to the corresponding angle, which leads to the corresponding movement of the slider of the potentiometer relative to its average position.

The direction of rotation of the flywheel of the control panel (motion of the slider relative to the midpoint) determines the sign of the speed, and the angle determines the value of the guidance speed. A DC voltage $U$ is applied to the potentiometer and voltage divider that are parallel connected. The voltages $U_{e x}$, applied to the control windings of the rotary amplifier form the total magnetic flow of the rotary amplifier and its output voltage $U_{a}$, respectively. The gearbox consists of a planetary gearbox, a safety clutch, a lifting clutch, a cogged cradle sector, and a balancing mechanism. The latter are two identical torsion bars (sets of steel plates), the elastic actions of which are counterdirected. This partially balances the lifting part of the combat vehicle, improves the process of damping of spring vibrations in the process of guiding a package of launch to a given angle, and also reduces the negative impact of backlash and gaps on the dynamics and statics of positioning of the package of launch.

The tachogram of motion of the electric drive $\omega(t)$ formed in the electromechanical guidance system has a significant influence on the parameters of the movement of the package of launch, on the accuracy of positioning of the package of launch and on the desired position - the angle of guidance.

Fig.2 shows a composite computer Simulink-model that structurally corresponds to the electromechanical system described above for the mechanism of vertical guidance of the BM-21 launch package. To model a drive engine in a computer Simulink-model created, we use a typical DC engine with independent excitation. This model is based on the following assumptions:

1) inductance of the anchor circle is unchanged (includes the inductance of the following elements: anchor $L_{a}$, windings of the additional poles $L_{a p}$ and compensation winding $(\mathrm{CW}) L_{c w}$ );

2) the anchor reaction is absent.

For constant and nominal excitation, a mathematical model of a drive engine is given by a system of differential equations:

$$
\left\{\begin{array}{l}
\frac{d i_{a}}{d t}=\frac{\left(U_{a}-C \omega\right) / R_{a}-i_{a}}{T_{a}} \\
\frac{d \omega}{d t}=\frac{M-M_{c}}{J},
\end{array}\right.
$$


where $C$ is the coefficient calculated as $C=k \Phi_{n} ; k=p_{n} N /(2 \pi a)$ is the engine design coefficient; $U_{a}$ is the voltage at the anchor of engine; $\omega$ is the angular speed of the engine shaft; $M$ is the electromagnetic moment at the engine shaft; $M_{c}$ is the moment of static load created by the mechanism of the guides, reduced to the axis of the engine shaft; $J$ is the moment of inertia of the anchor of the engine.

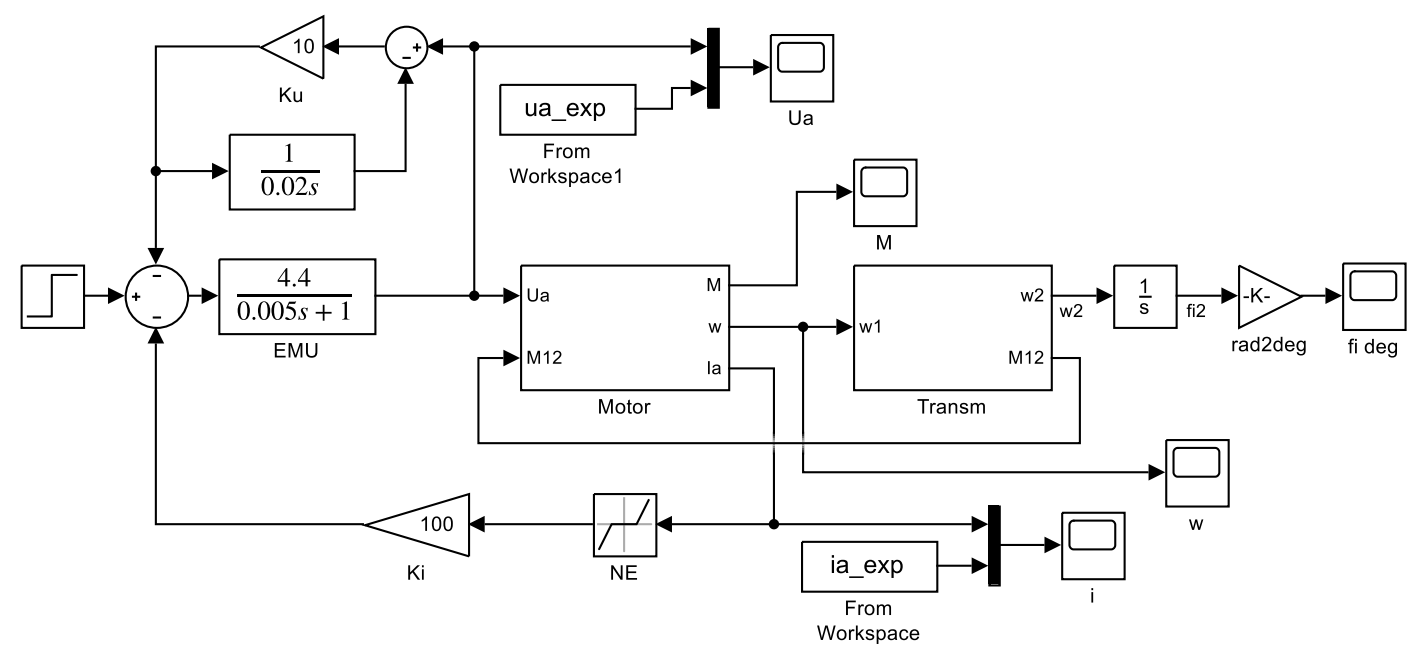

Fig.2. Simulink-model of the mechanism of vertical guidance of the package of launch of the combat machine BM-21.

The equation (1) corresponds to the structural model shown in Fig.3. In the developed Simulink-model (see Fig.2), this structural model is implemented by the "Motor" block, whose detailed structure is shown in Fig.4. In addition to the model of the engine described above, the created Simulink-model of the vertical guidance mechanism of the package of launch contains a model of rotary amplifier, which is a first-order link of chain (block EMU).

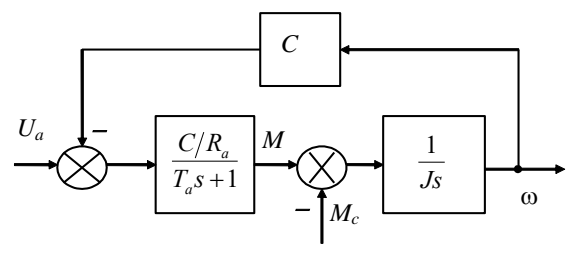

Fig.3. Structural model of constant current and rated current flow $\Phi=\Phi_{n}$ according to (1).

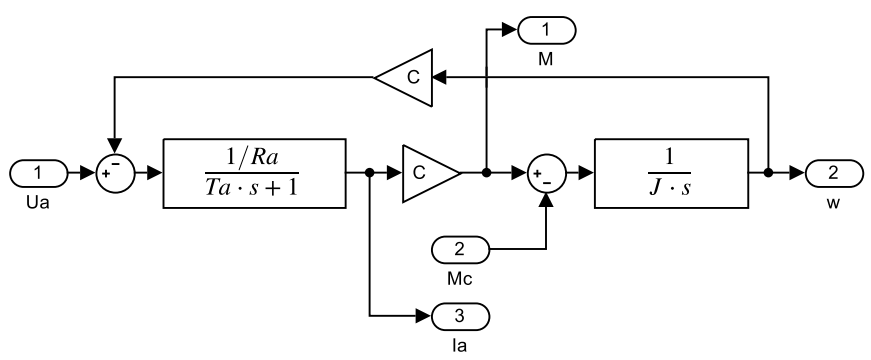

Fig.4. Internal structure of the "Motor" block (see Fig. 2)

The system operates the nonlinear (delayed) engine anchor current feedback (Ki and NE blocks) and the flexible (speeding up) feedback of the rotary amplifier voltage, which is implemented in the model by a proportional link (Ku block) covered by the feedback to the integral link, which together provide a model of a real differentiator.

The engine rotation speed from the output of the "Motor" block enters the input of the "Transm" subsystem - the model of the transmitting device, the internal structure of which is shown in Fig.5. The "Transm" block is leveling the elastic properties of the torsion-type balancing mechanism, the shaft's compliance (" $\mathrm{C}_{12}$ "), the effect of gaps ("Dead Zone") in the gearbox and the effect of the reactive load moment ("Sign"). The output signal of the "Transm" subsystem $\omega_{2}(t)$ (second mass velocity) is integrated in the block "Int1" $(\varphi(t)$ is a guidance angle in radians), and by 
the next block "rad2deg" is scaled into the guidance angle presented in degrees "fi_deg"- the angle of the vertical guidance of the package of launch in degrees. The moment of the first mass inertia (engine rotor) is taken into account in the model of the mechanical part of the engine (block "1/J.s" in Fig. 4).

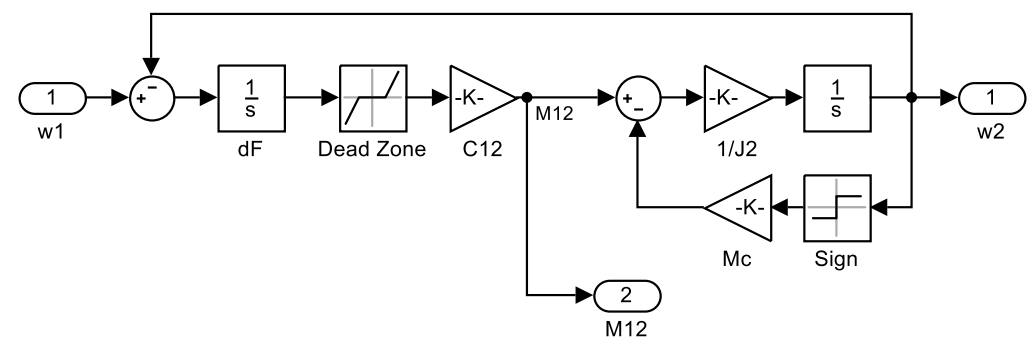

Fig.5. Internal structure of the "Transm” block (see Fig. 2).

The main parameters of the anchor drive engine circuit with independent excitation are the active resistance $R_{a}$, inductance $L_{a}$, and the time constant $T_{a}=L_{a} / R_{a}$. The parameters $R_{a}$ and $L_{a}$ are the sum of the corresponding parameters of all series connected components of the anchor circle of these vehicles: the windings of the anchors, the compensation windings, the windings of the additional poles. The value of the active resistance was determined when applying a low voltage to the winding of a stationary engine by the results of measurements of voltage and current according to the Ohm's law. The time constant of the anchor winding was determined by the experimentally taken responses of the anchor voltage to the input changing signal of the reduced value. An example of an experimentally taken curve of the anchor voltage and the model response of the electric part of a DC engine with independent excitation (block " $\left(1 / R_{a}\right) /\left(T_{a} \cdot s+1\right)$ " in Fig. 4) with the identified value of the time constant $T_{a}$ is shown in Fig. 6, c.

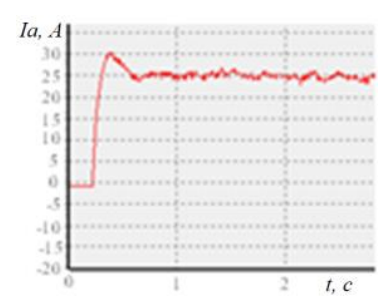

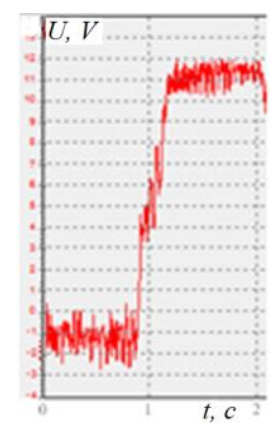

$b$

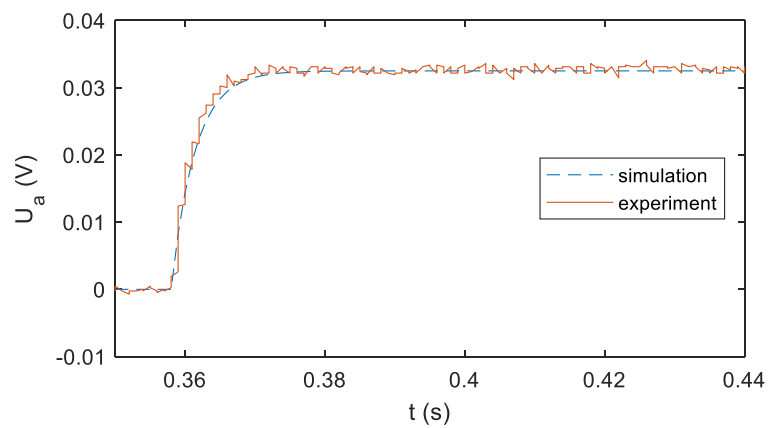

$c$

Fig.6. Example of the reaction obtained: $a$ - anchor current $I_{a}(t) ; b$ - voltage of the rotary amplifier; $c$ - experimentally taken curve of the anchor voltage and the response of the model of the electric part of the DC engine with the identified value of the time constant $T_{a}$.

The rotary amplifier in the created computer model of the electromechanical system is represented by a firstperiod aperiodic link. The procedure for determining the time constant of the $T_{E M U}$ rotary amplifier and of its static amplification factor $K_{E M U}$ was similar to that described above for a DC with independent excitation engine.

A number of experiments have been carried out at the experimental equipment, which allowed us to obtain estimates of the anchor current feedback coefficients and the parameters of the flexible feedback link on the rotary amplifier voltage.

Subsequently, the proposed Simulink-model was tested in operating modes of control and disturbing signals similar to those occurring in the real electromechanical system of the lifting mechanism of BM-21. The simulation results were compared with the experimentally obtained time dependencies of the coordinates, which were presented in digital form. This data was uploaded to the Matlab workspace and later used to verify the Simulink-model developed ("From Workspace" blocks in Fig. 2). In particular, the output of the block "ua_exp" represented the data experimentally obtained at the output of the voltage response amplifier, and the block "ia_exp" represented the experimentally recorded time dependencies of the anchor current).

The next step was to verify the created digital computer model. For this purpose, the estimates of the parameters and time dependencies of the coordinates changing of the investigated electromechanical guidance system were 
compared with the corresponding parameters and processes obtained by the created Simulink-model of the electromechanical mechanism of the guidance system, which used the identified parameters of its constituent elements. For some parameters of the elements, such as the moment of second mass inertia $J_{2}$, the coefficient of elasticity of the mechanical link $C_{12}$, the friction moment $M_{\mathrm{c} \text { fr }}$, as a component of the moment of static load of the mechanism of vertical guidance, and others, whose values cannot be determined with the required accuracy by the results of experimental studies. Their approximate values were obtained from the experiments performed or estimates of their values were obtained based on the analytical calculations performed. Subsequently, these values were refined in the course of optimization procedures with the involvement of the Matlab Optimization Toolbox software with respect to the criterion for minimizing the standard deviation between the dependencies experimentally obtained and the model time ones of the certain coordinates of the guidance mechanism. The parameters values obtained in this way were implemented in the computer Simulink-model of the electromechanical system of the guidance mechanism.

As an example, in Fig. 7, the time dependences of the change in voltage at the anchor $U_{a}(t)$ of the drive engine and the change in its current $I_{a}(t)$ at the acceleration interval of the drive, experimentally obtained at the lifting mechanism of the MLRS of BM-21, are demonstrated in a solid line (model curves are represented in a dashed line). In the experimental dependence there are pulsations on the curve $U_{a}(t)$ containing the frequencies in the range of 45-55Hz; they are the result of operating the polarized relay in the automatic control system (ACS). In the developed computer model, the effect of this polarized relay is not taken into account, since these pulsations are smoothed (filtered) by the electromechanical inertia of the drive engine of the system "rotary amplifier-DC engine" and do not appear in the time dependence of the shaft speed. In Fig. 7, b, the dependences of the anchor current of the engine $I_{a}(t)$ obtained experimentally (solid line) and obtained by the created computer model (dashed line) taken on a time interval of acceleration of the drive to a given (steady) speed of movement of the package of launch are shown. The computer time dependencies $U_{a}(t)$ and $I_{a}(t)$ (Fig. 7, dashed lines) are obtained as a result of optimization procedures, using as variant parameters the above-mentioned parameters of the EMS elements of the vertical guidance mechanism.

The analysis of both experimental and model reactions $U_{a}(t)$ and $I_{a}(t)$, shown in Fig. 7, for a single change of the setting signal (control effect) on the drive acceleration, confirms a sufficiently high level of coincidence of the main integral values of the dynamics indicators (transient time, overregulation, oscillation, standard error of discrepancy, etc.). The integral estimates of the standard deviation of experimental and model reactions $U_{a}(t)$ and $I_{a}(t)$ are $10,425 \mathrm{~B}$ and $4,733 \mathrm{~A}$ for the anchor voltage and current, respectively. The values of the variational parameters obtained in these experiments are implemented in the Simulink-model of the EMS mechanism of guidance of the package of guides.
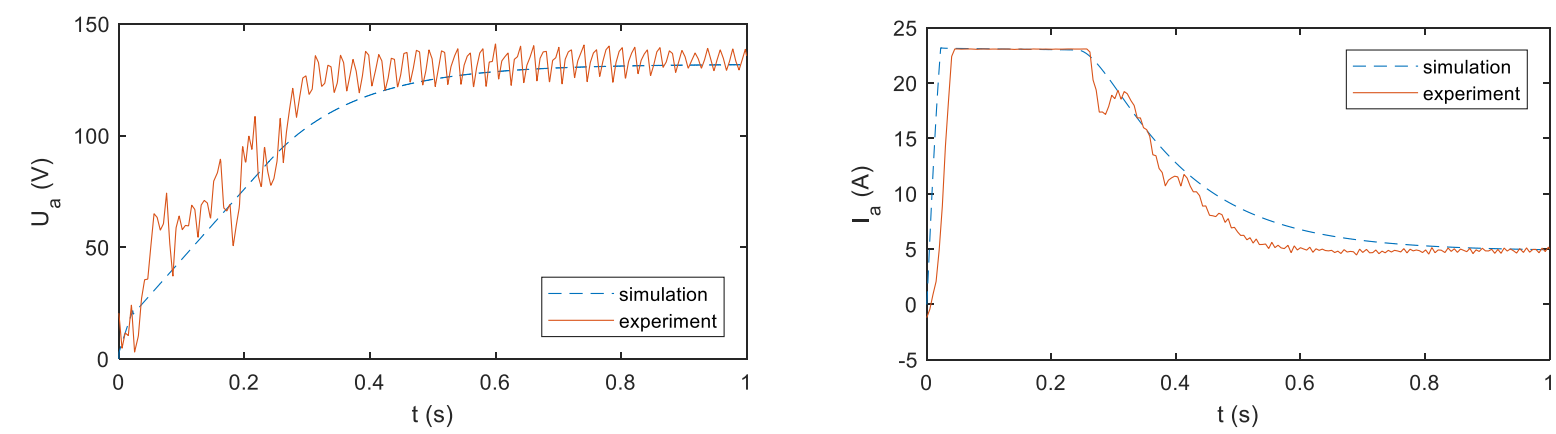

Fig.7. Experimental (-) and model (- - -) reactions $U_{a}(t)$ and $I_{a}(t)$ on a single change of the control signal on moving the package of guides.

In Fig. 8, the experimental dependences obtained in the process of experimental investigations (see Fig.8, a) and by the created computer model (see Fig. 8,b) of the EMS to ensure motion of the package of guides on the BM-21 are shown as well as the time dependencies of the change of the guidance angle $\varphi(t)$ in displacement of the package of guides from zero position by the angle of $60^{\circ}$ with a short stop at $35^{\circ}$.

The electrical and mechanical parts of guidance of the armament of a combat vehicle are characterized by the multicomponent and specific features of their constituent elements. Accordingly, the mathematical model of such an electromechanical system is also complex. When synthesizing the optimal dynamics of such a system, that is, to implement high speed and static accuracy with respect to the angle of guidance of the package of guides, as well as to obtain the invariance of these EMS properties from parametric changes and coordinate perturbations of the control object, it is necessary to use special techniques. These techniques should take into account the elastic elements present in the mechanical system, in particular, the torsion bar mechanism, and nonlinearity - the backlash in the 
mechanical transmissions, the change of the parameters and the moment of inertia of the kinematic scheme under different loads of the package of guides, the change of the total moment of static load in the process of guidance of the package of guides at different angles and under different loading of guides with shots, etc. It is impossible to do this based on the classic automatic control theory techniques. Moreover, difficult to solve is the task of adapting the desired indicators of the dynamics of the guidance system to the changes of the above-mentioned factors.
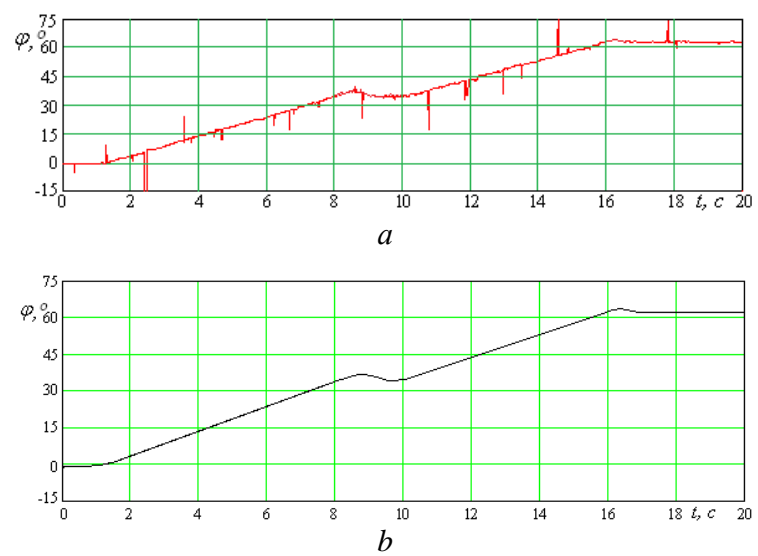

Fig.8. Experimental $(a)$ and computer $(b)$ time dependencies of the angle of guidance $\varphi(t)$ of the package of guides.

Therefore, for such EMS characteristics to ensure the motion of the package of guides, the expedient, in our opinion, approach to obtain the desired (optimal) dynamics and statics is to use modern methodology and systems engineering of intelligent control, in particular, the use of fuzzy control in the structure of the SAC of motion of the package of guides, in particular, the use of fuzzy correctors and regulators in the structure of the control system. Designed on the basis of this approach, the SAC will meet the conditions of obtaining the desired dynamics not only in the vicinity of the point of the most probable angle of the positioning of the package of guides but also when moving the package of guides into any other positions. With this, the requirements for the dynamics and statics indicators in the complete range of changes the parameters and disturbing influences of the dynamic nonlinear system of the mechanism of guidance of the package of guides will be observed.

The created Simulink-model of the EMS mechanism of guidance of the package of guides will be an effective tool for performing the tasks of structural and parametric synthesis and analysis of dynamic and static properties of such a system based on a nonlinear model of its description, which will be the subject of further research. Carrying out the relevant mathematical experiments and performing the computer model studies allow us to fully investigate the quality of the guidance process and obtain dynamics and statics estimates in the driving and deceleration modes of the electric drive in the real ranges of changing the setting and disturbing effects, parametric changes in the vertical guidance mechanism, and to perform parametric optimization of the EMS mechanism of guidance of the package of guides of a combat machine.

\section{Conclusion}

In order to improve the control system of the electromechanical system of the lifting mechanism of the BM-21 combat vehicle in the direction of increasing the speed of the guidance process, the accuracy of positioning, and reducing its overall dimensions and cost, its mathematical and computer models have been developed.

According to the results of the experimental investigations, the models of individual units and parameters of the elements of the electrical and mechanical parts of the lifting mechanism of the BM-21 combat vehicle have been obtained.

The expediency of performing as well as the optimization procedure in the identification of unmeasurable parameters and characteristics of the guidance mechanism for constructing the structural Simulink-model of the automatic control system of guidance of the package of guides using mathematical and computer simulations are substantiated.

The analysis of estimates of the parameters and processes of the changes of coordinates of the electromechanical system of providing the motion of a package of guides, which are obtained by means of the created computer model 
and experimentally on the operating combat machine has shown a sufficiently high accuracy of their coincidence, which confirms the adequacy of the created computer Simulink-model of the electromechanical system of the mechanism of guidance of the package of guides of the armament complex of a combat machine BM- 21 .

\title{
References
}

[1] Blokhin L.M., Sytnychenko N.D. and Kukhar V.V. (2012) New challenges synthesis algorithm of optimal structures observers output coordinates dynamic objects. Problems of Informatization and Management, 4 (40), 19-23. http://dx.doi.org/10.18372/2073-4751.4.7666 (in Ukrainian)

[2] Shiyko O.M. (2014) Design of joint motion of jet-projectile and mobile starting setting. Systems of Arms and Military Equipment, 2 (38), 4460. (in Ukrainian)

[3] Kuntsevich V.M. (2006) Control under uncertainties: guaranteed results in the problems of control and identification. Naukova dumka, Kyiv. (in Russian)

[4] Rutkovskiy A.L., Matveyeva L.I. and Kozachek G.V. (2010) Optimization of factors of transmission function, got by modified method by Simoyu according to the experimental skim connection feature. Proceedings of Voronezh State Technical University, 3. (in Russian)

[5] Alikov A.Yu., Kovaleva M.A., Rutkovskiy A.L. and Tedeeva N.V. (2017) Automation of optimal identification of dynamic element transfer functions in complex technical objects based on acceleration curves. Proceedings of Daghestan State Technical University. Technical Sciences, 44 (2), 97-106. http://dx.doi.org/10.21822/2073-6185-2017-44-2-97-106 (in Russian)

[6] Smilgevicius A. and Rinkeviciene R. (2005) Simulation of transients in the mechanical part of electromechanical system. Mathematical Modelling and Analysis 2005. Proceedings of the 10th International Conference MMA2005 \& CMAM2, Trakai, Lithuania, June 1-5, 2005, 155-162.

[7] Bolognani S., Venturato A. and Zigliotto M. (2000) Theoretical and experimental comparison of speed controllers for elastic two-masssystems. 2000 IEEE 31st Annual Power Electronics Specialists Conference, Galway, Ireland, 23-23 June 2000, 3, $1087-1092$. http://dx.doi.org/10.1109/PESC.2000.880463

[8] Feiler M., Westermaier C. and Schroder D. (2003) Adaptive speed control of a two-mass system. Proc. of 2003 IEEE Conference on Control Applications. CCA 2003., Istanbul, Turkey, 25 June 2003, 2, 1112-1117. http://dx.doi.org/10.1109/CCA.2003.1223166

[9] Gernet M. and Ratobylsky V. (1969) Determination of moments of inertia. Mashinostroyeniye, Moscow. (in Russian)

\section{Верифікація комп'ютерної Simulink-моделі електромеханічної системи механізму наведення комплексу озбросння бойової машини}

\author{
Ярослав Паранчук ${ }^{a}$, Павло Євдокімов ${ }^{b}$, Олексій Кузнєцов $^{b}$, Володимир Цяпа $^{a}$ \\ ${ }^{a}$ Національний університет «Львівська політехніка», вул. С. Бандери, 12, Львів, 79013, Україна \\ ${ }^{b}$ Національна академія сухопутних військ імені гетьмана Петра Сагайдачного, \\ вул. Героїв Майдану, 32, Львів, 79026, Україна
}

\section{Анотація}

Удосконалення існуючих електромеханічних систем наведення комплексу озброєння бойових машин повинно відбуватись у напрямі підвищення швидкодії та точності позиціонування. У роботі розглянуто підйомний механізм наведення пакету напрямних реактивної системи залпового вогню БМ-21, що стоїть на озброєнні Збройних Сил України та є типовою для багатьох зразків озброєння. На основі опрацювання експериментально отриманих часових залежностей координат існуючої електромеханічної системи надання вертикального руху пакету напрямних проведено ідентифікацію параметрів та передавальних функцій ії елементів, які реалізовано у математичній та комп’ютерній Simulink-моделі. Виконано порівняння процесів зміни координат у процесі наведення, які отримано на створеній іï комп'ютерній моделі і діючій бойовій машині. Порівняння отриманих результатів показали досягнення достатньої точності співпадіння часових залежностей координат електромеханічних систем наведення.

Ключові слова: система наведення озброєння; точність позиціонування; швидкодія; комп'ютерна модель. 